Wong, S.W. \& Yuen, M. (2015). Super's Work Values Inventory: Issues of subtest internal consistency using a sample of Chinese university students in Hong Kong. Journal of Employment Counseling, 52 (1), 29-35. DOI: 10.1002/j.2161-1920.2015.00054.x

\title{
WORK VALUES
}

\section{Super's Work Values Inventory: Issues of subtest internal consistency using a Chinese university student sample in Hong Kong}

\author{
Shui-wai Wong \&Mantak Yuen
}

Submitted to Journal of Employment Counseling June 2013

Revised and re-submitted to Journal of Employment Counseling August 2013

Shui-wai Wong: Department of Applied Social Sciences, Hong Kong Polytechnic University, Hung Hom, Hong Kong, China;

MantakYuen:Center for Advancement in Inclusive and Special Education,Faculty of Education, University of Hong Kong, Pokfulam Road, Hong Kong, China;

Acknowledgment: This paper is based on the first author's doctoral dissertation completed under the supervision of the second author.

Correspondence concerned this article should be addressed to Mantak Yuen, Centre for Advancement in Inclusive and Special Education, Faculty of Education, University of Hong Kong,Pokfulam Road, Hong Kong, China.E-mail: mtyuen@hku.hk 


\title{
Super's Work Values Inventory: Issues of subtest internal consistency using a Chinese university student sample in Hong Kong
}

\begin{abstract}
This paper discusses observed weaknesses in internal consistency (Cronbach

Alphas below 0.60) within five subtests of the Work Values Inventory when translated into Chinese and used with a sample of 211 university students in Hong

Kong. Possible reasons for the weaknesses are explored, and suggestions are made for improvement.
\end{abstract}

Keywords:

Chinese; Hong Kong; university students; Work Values Inventory 
Work values is the term used to describe the feelings, attitudes and beliefs that an individual may hold in regard to employment in general, and to specific types of work or occupation in particular (Ros, 1999; Super, 1995). The concept usually embraces such diverse attributes as: the prestige associated with a job, remuneration, job security, working environment, work colleagues; and personal qualities such as work ethic, willingness to work in a team, professionalism, loyalty, integrity, dependability, achievement motivation, initiative and satisfaction.

The field of career guidance and counseling in universities has long recognized that the work values an individual holds represent important influences on his or her career decision-making (Ben-Shem \& Avi-Itzhak, 1991; Carruthers,1968; Duffy \&Sedlacek, 2007; Judge \& Bretz, 1992; Super, 1995). For this reason, work values are often included as part of any formal assessment that is made when a university student seeks career guidance. Knowledge of the student's work values can then help identify appropriate (and inappropriate) career choices. This assessment can be accomplished by using a work values inventory, along with evaluation of personality, aptitude, skills and interests, to help match the individual with the known characteristics of different occupations (Athanasou \& Van Esbroeck, 2008; Whitfield, Feller \&

Wood, 2009).

A work value inventory usually provides a list of hypothetical 'values', and the respondent is asked to rate the importance of each item. One such inventory, widely used for over forty years 
in Western research studies, is Super's (1968) 45-item Work Values Inventory (WVI). It seeks to measure fifteen values orientations. In the original trials by Super, a median of 0.83 for test-retest reliability of subscales was reported, and validity was established by correlating WVI with the Allport-Vernon-Lindzey Study of Values, Strong Vocational Interest Blank and the Kuder Preference Record (Vocational) (Super, 1968).

Other empirical support exists for the reliability and validity of WVI (Chu, 2008; Hendrix \& Super, 1968)—and also for Zytowski's (2006) revised version with 72 items but only 12 subscales (WVI-R)(Hammond et al., 2010; Leuty, 2013; Robinson \& Betz, 2008).The 72-item version obviously takes longer to administer and interpret, so for convenience Chu (2008) used the original 45-item WVI with Chinese students in Taiwan. This version was also adopted for the study reported here, involving 211 university students in Hong Kong.These researchers intendedto identify an instrument that would be of practical value in university career guidance contexts. WVI was chosen because of its frequent use in other research, its face validity (Staats,1981), its ease of administration and scoring, and its clearly stated items (Kanchier\& Unruh, 1989). The English version of WVI was translated into Chinese by the author (a social scientist) and a psychologist, back translated to English by a bilingual English teacher, and finally both English and back-translated versions were compared and confirmed for equivalence by another bilingual English teacher. 
This brief paper discusses some issues related to the internal consistency of some of the subscales, as revealed by this sample of respondents. For other aspects of the use of WVI with Hong Kong Chinese students (factor structure and discriminant validity) see Wong and Yuen (2013).

METHOD

Participants

The 211 volunteer participants from five universities in Hong Kong were full-time Chinese undergraduate students $(37.4 \%$ male; age range 18 to 25 , with mean age 20.4 years; $44.3 \%$ freshmen, $34.3 \%$ sophomores, $19.5 \%$ juniors, $1.9 \%$ seniors). Areas of study included business (25.4\%), engineering, mathematics, physical science (24.4\%), social andbehaviouralsciences (23.0\%), health care education (mainly nursing andoptometry)(15.8\%), arts andhumanities (10.5 $\%)$ and education (1.0\%).

Participation was voluntary,without any material rewards, and recruitment was achieved by convenience sampling through staff of the Student Affairs Office and academic departments in the five Universities who helped distribute questionnaires in classes or during student activities. The study was approved by the Human Research Ethics Committee for Non-Clinical Faculties at the University of Hong Kong. 


\section{Procedure}

The Chinese version of Super's Work Values Inventory was distributed to all participants for them to complete privately in their own time. These questionnaireswere then returned anonymously between January and April, 2011. At the same time basic demographic information was collected from each participant(gender, age, year of study, course of study).

Measure

Super's Work Values Inventorycontains 45 items, forming 15 subscales. The response format uses a five-point Likert-type scale, ranging from 1 (unimportant) to 5 (very important). The 15 subscales can be further categorized as intrinsic, extrinsic, and concomitants. The reliability and validity of the WVI have been thoroughly tested (Neuman, Pizam\&Reichl, 1980). The Chinese version has been validated by Wong and Yuen (2013).

Analysis of data

In the first stage, all data were subjected to tests for normality of distribution.

Mean ratings for each subscale were then computed, along with the relevant CronbachAlphas.

Subsequent analyses involved Exploratory Factor Analysis with Varimax rotation to determine the factor structure of WVI with this Chinese sample. The factor structure obtained is discussed in Wong and Yuen (2013). This paper looks only at issues of instrument reliability.

\section{RESULTS}




\section{Item analysis}

Table 1 summarizes the Cronbach Alphas, inter-item correlations, means, and standard deviations for WVI in this Chinese university student sample. All calculations are based on respondents' raw scores obtained from the relevant subscales.

\section{[PLACE TABLE 1 ABOUT HERE]}

In terms of internal consistency (the extent to which all items in a subtest are similar in content), Cronbach Alphas for the WVI subscales ranged from .42 to .90 , with most values falling between .60 and .80 .The most internally consistent subscales were those assessing values associated with Creativity (.90), Altruism (.84), and Economic Returns (.81). This is in contrast to the subscales covering Aesthetics (.42) and Way of Life(.49), both revealing weaker internal consistency. Only slightly higher Alphas were associated with Achievement (.50), Prestige (.57) and Independence (.57). These consistency figures from the five subscales are below the level usually considered the benchmark for a reliable assessment scale (Nunnally \& Bernstein, 1994;

DeVellis, 2003). Similar findings of weak reliabilities in several WVI subscales, particularly Way of Life (.44), Independence (.44), Prestige (.53), Associates (.53), and Intellectual Stimulation (.56) had also been reported by Gable and Pruzek (1971), with high school students in the U.S.

To determine whether the 45 separate items in WVI were all yielding useful information, further item analysis was conducted. It was found that, despite the data falling within an 
acceptable range of skewness and kurtosis (according to test), some responses were actually biased towards 'strongly agree' or 'important to me' (scoring 4-5). A skewed distribution with a value slightly exceeding -1.0 was found in item 11 ('[I value having $].$. a boss who gives you a fair deal'), item 19 (' $\ldots$ sure of always having a job'), item 22 (' $\ldots$ pay increases that keep up with the cost of living'), and item 35 ('...lead the kind of life you most enjoy'). This suggests strongly that these items have poor discriminatory power, because most respondents rate them very highly. It is most unlikely, for example, that any respondent would not value a fair boss, or wages that keep up with inflation.

It was also observed that the corrected item-total correlationsfor Item 5 '[I value]...having freedom in my area', Item 10 '...can be the kind of person I would like to be', and Item 20 ' $\ldots$ adding beauty to the world' were below 0.3 ( $0.295,0.224$, and 0.098 respectively), so these items might also adversely affect the reliability of the respective subscales.

\section{DISCUSSION}

A probable explanation for weak internal consistency in measuring instruments of this type is found in the conclusion reached by Schwartz et al. (2001) — namely that values measures often tend to have very few items (two or three) per subscale, and the instrument trieswithin those few items to covera range of values or attributes. For example, items assessing a valueassociated with 'prestige work' might attempt to embracespecific values as diverse as 'high 
social status', 'good reputation' and 'high level of importance'.

Due to the nature of data typically collected in the social sciences, researchers havebegun to question the wisdom of depending entirely on hypothetical cut-off points for judging a scale's internal reliability (Brunner \&SÜb, 2005; Schmitt, 1996; Spiliotopoulou, 2009).According to Gay and Airasian (2000, p.177), "It is extremely difficult to state appropriate coefficients for different types of tests.'Instrumentstypically used in social sciences research need to have good test-retest reliability(stability), good construct and content validity,and good inter-scorer agreement — but it may be acceptable to tolerate weaker internal consistency within subscales if the items themselves yield useful information (Schmitt, 1996). As stated above, the full WVIscale and WVI-Rhave gained a reputation for high test-retest reliability (Chu, 2008; French, 1971; Hendrix \& Super, 1968; Robinson\&Betz, 2008;Super, 1968) and for construct validity (Robinson and Betz, 2008; Wong \& Yuen, 2013).

As the study reported here was conducted with Chinese subjects, it is relevant to consider how differences in general values and work values held across different cultural groups might affect individuals'responses to subscales in WVI. This could have an impact upon the scale's internal consistency. It is possible that psychometric features of WVI (including internal consistency) may be 'sample specific'. In this study, there are significant cultural differences between Hong Kong Chinese students and those in Western countries; and there are even subtle 
cultural differences between populations of Chinese people living in different localities (e.g.,

Mainland China, Taiwan, Hong Kong, Macau, Singapore). Hong Kong was a British colony until 1997, and developed a unique values system that combinesWestern values with traditional Chinese values derived from Confucianism and Taoism.Hong Kong Chinese people tendto believe in hard work, respect for order and authority,accept unequal distribution of power, and regard the questioning of authority as disrespectful and 'un-Confucian'(Hofstede, n.d.; Becton \& Field, 2009). Western countries, by comparison, tend to be more individualistic in work values orientation(Chen \&Partington, 2004).

The interplay of both Chinese and Western values may cause Hong Kong Chinese subjects to respond inconsistently to certain culturally sensitive items in WVI, resulting in greater variability within some subscales. As an example, Chinese people are well known for possessing a strong material tendency, focusing on personal life (Lin, 1980; Chong \& Liu, 2002) rather than on making a major contribution to the aesthetic aspects of life. Some respondents may therefore place low value on item 20 "add beauty to the world" (extremely low Item-Total Correlation Coefficient of 0.098). Another well-known feature of Chinese cultureis a collectivistic orientation(Gao\&Kotey, 2008). Item 10 in WVI asks them if they value work that would enable them to be “... the kind of person you would like to be".Perhaps these Chinese respondents saw thisvalue as too individualistic and did not rate the item highly (low Item-Total Correlation 
Coefficient (0.224). In subscales with very few items, inconsistent response patterns of this type can affect internal consistency.

One way to improve the internal consistency of WVI subscales would be to add new items to make the test longer (as was done by Zytowski, 2006) in order to better encompass the full range of attributes and examples associated with each work value. It would also be advisable to reword (or replace) those items that tend to draw responses skewed heavily toward the most positive rating—or that are culturally sensitive.

Future research could also compare the internal consistencies/reliability of both WVI and WVI-R (Robinson \& Betz, 2008; Zytowski, 2006) if translated into Chinese, in order to determine the better option for career assessment and counseling in the Hong Kong context.

\section{References}

Athanasou, J. \& Van Esbroeck, R.(2008).International handbook of career guidance.Doordrecht: Springer.

Becton, J. B. \& Field, H. S. (2009). Cultural differences in organizational citizenship behavior: A comparison between Chinese and American employees. The International Journal of Human Resource Management, 20, 1651-1669.

Ben-Shem, I., \&Avi-Itzhak, T. E. (1991). On work values and career choice in freshmen studies: The case of helping vs. other professions. Journal of Vocational Behaviour, 39, 369-379. 
Brunner, M., \&SÜb, H. M. (2005).Analyzing the relationship of multidimensional measures: An example from intelligence research.Educational and Psychological Measurement, 65, 227-240. doi: 10.1177/0013164404268669

Carruthers, T. E. (1968). Work values and chosen careers: Note on a trial of an American Work Value Inventory with British subjects. Occupational Psychology, 42, 111-117.

Chen, P., \&Partington, D. (2004).An interpretive comparison of Chinese and Western conceptions of relationships in construction project management work.International Journal of Project Management, 22, 397-406.

Chong, F. H. H.,\& Liu, H. Y. (2002). Indigenous counseling in the Chinese cultural context: Experience transformed model. Asian Journal of Counselling, 9, 49-68.

Chu, K.H.L. (2008). A factorial validation of work value structure: Second-order confirmatory factor analysis and its implications. Tourism Management, 29, 320-330. doi:10.1016/j.tourman.2007.03.003

DeVellis, R. F. (2003). Scale development: Theory and applications ( $2^{\text {nd }}$ ed.). Thousand Oaks, CA: SAGE.

Duffy, R. D., \&Sedlacek, W. E. (2007). The work values of first-year college students: exploring group differences. The Career Development Quarterly, 55, 359-364.

French, J. W. (1971). Reviewed work: Work Values Inventory by Donald E. Super.Journal of 
Educational Measurement, 8, 53-54.

Gable, R. K., \&Pruzek, R. M. (1971). Super's Work Values Inventory: Two multivariate studies of inter-item relationships. The Journal of Experimental Education, 40, 41-50.

Gao, K.,\&Kotey, B. (2008). Chinese values and SME strategy in the Chinese economic transition: How close are they to the West?Retrieved from:

http://sbaer.uca.edu/research/sbi/2008/chald2s.html

Gay, L. R., \&Airasian, P. (2000).Educational research: Competencies for analysis and application ( $6^{\text {th }}$ ed.). Upper Saddle River, NJ: Merrill.

Hammond, M. S., Betz, N. E., Multon, K. D., \& Irvin, T. (2010).Super's Work Values Inventory-Revised Scale validation for African Americans.Journal of Career Assessment, 18, 266-275. doi: 10.1177/1069072710364792

Hendrix, V. L., \& Super, D. E. (1968).Factor dimensions and reliability of the Work ValuesInventory.Vocational Guidance Quarterly, 17, 269-274.

Hofstede, G. (n.d.). What about Hong Kong? Retrieved from:http://geert-hofstede.com/hong-kong.html

Judge, T.A.,\&Bretz, R.D. (1992).Effects of work values on job choice decisions.Journal of Applied Psychology, 77(3), 261-271. doi: 10.1037/0021-

9010.77.3.261 
Kanchier, C., \& Unruh, W. R. (1989). Work values: How do managers who change jobs differ from those who do not? Journal of Employment Counseling, 26, 107-116.

Leuty, M. E. (2013). Stability of scores on Super's Work Values Inventory-Revised.

Measurement and Evaluation in Counselling and Development, 46, 3: 202-217.

Lin, K. M. (1980). Traditional Chinese medical beliefs and their relevance for mental illness and psychiatry. In A. Kleinman\& T. Y. Lin (Eds.), Normal and abnormal behaviour in Chinese culture (p.95-111). Dordrecht, Holland: Reidel.

Neuman, Y., Pizam, A., \&Reichel, A. (1980). Values as determinants of motivation: Tourism and other career choices. Annals of Tourism Research, 11, 428-442.

Nunnally, J. C., \& Bernstein, I. (1994).Psychometric theory ( $3^{\text {rd }}$ ed.). New York: McGraw-Hill.

Robinson, C. H., \& Betz, N. E. (2008). A psychometric evaluation of Super's Work Values Inventory-Revised. Journal of Career Assessment, 16, 456-473. doi: $10.1177 / 1069072708318903$

Ros, M. (1999). Basic individual values, work values, and the meaning of work. Applied Psychology: An International Review, 48, 1: 49-71.

Schmitt, N. (1996). Uses and abuses of coefficient alpha.Psychological Assessment, 8, 350-353. 
Schwartz, S. H., Gila Melech, A. L., Steven B. M., \& Vicki, O. (2001). Extending the cross-cultural validity of the theory of basic human values with a different method of measurement.Journal of Cross-Cultural Psychology, 32, 519-542.

doi:10.1177/0022022101032005001

Spiliotopoulou, G. (2009). Reliability reconsidered: Cronbach's alpha and paediatric assessment in occupational therapy. Australian Occupational Therapy Journal, 56, 150-155.

Staats, S. (1981). Work Values Inventory scores from 1970 to 1980. Perceptual and Motor Skills, $53,113-114$.

Super, D.E. (1968).Manual for work values inventory. Boston, MA: HoughtonMifflin Company.

Super, D. E. (1995). Values: Their nature, assessment, and practical use. In D. E. Super \& B. Sverko (Eds.),Life roles, values and careers: International findings of the Work Importance Study (p. 54-61). San Francisco: Jossey-Bass.

Whitfield, E.A., Feller, R.W., \& Wood, C. (Eds.). (2009). A counselor's guide to career assessment instruments (5th ed.). Broken Arrow, OK: National Career Development Association.

Wong, S.W., \& Yuen, M.(2013). Evaluating Super's Work Values Inventorywith University Students in Hong Kong. Manuscript submitted for publication.

Zytowski, D. G. (2006).Super's Work Values Inventory-Revised: Technical manual. Retrieved 
from www.kuder.com/downloads/SWV-Tech-Manual.pdf 
Table 1.

Cronbach Alphas, Inter-item Correlations, Means, and Standard Deviations for WVI in the Chinese student sample

\begin{tabular}{|c|c|c|c|c|c|}
\hline $\begin{array}{l}\text { WVI } \\
\text { Subscale }\end{array}$ & $\mathrm{N}$ & $\begin{array}{c}\text { Cronbach's } \\
\text { Alpha }\end{array}$ & $\begin{array}{c}\text { Average } \\
\text { Inter-item } \\
\text { correlation }\end{array}$ & Mean & SD \\
\hline Creativity & 211 & .901 & .752 & 10.4360 & 2.67785 \\
\hline Management & 210 & .771 & .531 & 9.4524 & 2.38017 \\
\hline Achievement & 209 & .502 & .261 & 12.1292 & 1.60155 \\
\hline Surroundings & 211 & .641 & .388 & 12.3460 & 1.72619 \\
\hline Supervisory Relations & 211 & .777 & .541 & 12.8436 & 1.72908 \\
\hline Way of Life & 211 & .494 & .275 & 12.2701 & 1.76959 \\
\hline Security & 211 & .689 & .440 & 11.5829 & 2.31074 \\
\hline Associates & 211 & .629 & .410 & 12.5877 & 1.71981 \\
\hline Aesthetics & 210 & .420 & .363 & 9.3143 & 2.19314 \\
\hline Prestige & 211 & .571 & .315 & 11.1232 & 1.99141 \\
\hline Independence & 210 & .570 & .300 & 10.8619 & 1.89812 \\
\hline Variety & 211 & .762 & .519 & 9.9194 & 2.48580 \\
\hline Economic Returns & 211 & .805 & .580 & 12.6493 & 1.99051 \\
\hline Altruism & 211 & .837 & .630 & 11.2085 & 2.33893 \\
\hline Intellectual & 211 & .653 & .386 & 10.5166 & 2.09840 \\
\hline Stimulation & & & & & \\
\hline
\end{tabular}

